\title{
A TV Multimídia nas Práticas Pedagógicas dos Professores nas Escolas Públicas do Estado do Paraná: um diagnóstico a partir da Teoria da Atividade
}

\author{
The Multimedia TV in Paraná State Public Teachers' Pedagogical Practice: a \\ diagnosis based on Theory of Activity
}

\begin{abstract}
La TV Multimedia en las Prácticas Pedagógicas de los Profesores en las Escuelas Públicas del Estado de Paraná: un diagnóstico a partir de la Teoría de la Actividad
\end{abstract}

\author{
Cleber Bianchessi ${ }^{1}$
}

Ademir Aparecido Pinhelli Mendes ${ }^{2}$

\begin{abstract}
RESUMO: O artigo apresenta o resultado de uma investigação a respeito do uso da TV Multimídia nas práticas pedagógicas dos professores da Rede Pública Estadual do Paraná. Identifica a importância e a contribuição do aparelho para o processo de ensino e aprendizagem, bem como analisa a percepção docente acerca da permanência do equipamento no espaço escolar. Trata-se de uma pesquisa de abordagem metodológica quantiqualitativa com aplicação de questionário aos professores pelo formulário Google. Os dados coletados foram analisados por meio da Teoria da Atividade (LEONTIEV, 2014) a fim de compreender o processo em sua totalidade. Na pesquisa foram encontradas evidências de que os docentes que fazem uso do equipamento atribuem significação à sua experiência pedagógica mediada pelo instrumento tecnológico. Constatou-se que grande parte dos professores que responderam ao questionário utiliza a TV Multimídia, já que é o único equipamento multimídia disponível em sala de aula.
\end{abstract}

PALAVRAS-CHAVE: Teoria da atividade. TV multimídia. Novas tecnologias.

ABSTRACT: This article presents the result of an investigation about the use of Multimedia TV in the Paraná State web public Teachers' pedagogical practices. It identifies the importance and contribution of the apparatus to the teaching and learning process, as well as analyzes the teacher's perception about the permanence of the equipment in the school space. This is a qualitative methodological research, with questionnaire application to teachers through the Google form. The collected data were analyzed through the Theory of Activity (LEONTIEV, 2014) in an attempt to understand the process in its entirety. The research found evidence that teachers who use the equipment attribute meaning to their pedagogical experience mediated by the technological instrument. It is observed that a large part

\footnotetext{
1 Mestre em Educação e Novas Tecnologias. Rua Lamenha Lins, 635, Apto 1801 - CEP 80250-020 Bairro Batel Curitiba- PR. cleberbian@yahoo.com.br.

2 Doutor em Educação. Professor Titular do Mestrado em Educação e Novas Tecnologias do Centro Universitário Internacional Uninter. Avenida Iguaçu, no 2121 - Apto. 21, Bloco B. CEP 80.240.030, Curitiba - Paraná. ADEMIR.M@uninter.com.
} 
A TV Multimídia nas Práticas Pedagógicas dos Professores nas Escolas Públicas do Estado do Paraná...

of the teachers who answered the questionnaire use TV Multimedia, as it is the only multimedia equipment available in the classroom.

KEYWORDS: Theory of activity. TV multimedia. New technologies.

RESUMEN: El artículo presenta el resultado de una investigación acerca del uso de la TV Multimedia en las prácticas pedagógicas de los profesores de la Red Pública Estadual de Paraná. Identifica la importancia y contribución del aparato para el proceso de enseñanza y aprendizaje, así como analiza la percepción docente acerca de la permanencia del equipo en el espacio escolar. Se trata de una investigación de enfoque metodológico cuanticualitativa, con aplicación de cuestionario a los profesores a través del formulario Google. Los datos recolectados fueron analizados por medio de la Teoría de la Actividad (LEONTIEV, 2014), en el intento de comprender el proceso en su totalidad. En la investigación se encontraron evidencias de que los docentes que hacen uso del equipo atribuyen significación a su experiencia pedagógica mediada por el instrumento tecnológico. Se constata que gran parte de los profesores que respondieron el cuestionario utilizan la TV Multimedia, ya que es el único equipo multimedia disponible en el aula.

PALABRAS-CLAVE: Teoría de la actividad. TV multimedia. Nuevas tecnologías.

\section{INTRODUÇÃO}

A instalação da TV Multimídia nas salas de aula das escolas públicas paranaenses foi uma iniciativa da gestão do Governador Roberto Requião, no ano de 2007. Houve investimentos de aproximadamente 20 milhões de reais para instalar o equipamento em mais de 22 mil salas de aulas, em todos os estabelecimentos estaduais. Popularmente conhecida no meio educacional como TV Pendrive (termo que será adotado neste artigo a partir desta definição), devido à distribuição de um pendrive para a comunidade escolar na época da instalação, é possível caracterizá-la conforme definição de Jackiw (2011), segundo o qual a TV multimídia é um aparelho televisor de 29 polegadas que possui cor alaranjada e por meio do qual é possível exibir áudio, vídeo e imagens em diversos formatos. Sequencialmente, os professores foram beneficiados com um pendrive com capacidade de dois gigabytes. Essa situação causou surpresa e espanto para os docentes e as equipes diretivas, que não tinham conhecimento daquele movimento, pois não tinham sido consultados sobre esta modificação da sala de aula. De acordo com Silva (2016) que foram entregues aos professores cartões de memória e/ou pen drives que poderiam ser lidos pelos aparelhos de TV. Tal ação da gestão pública produziu naquela época forte impacto no espaço escolar, já que grande parte dos professores desconhecia aquele recurso tecnológico, inserido repentinamente e sem nenhum tipo de consulta a respeito da necessidade de sua instalação. Por outro lado, criou-se grande expectativa de que tal equipamento melhoraria $o$ ambiente escolar, facilitando o processo de ensino e 
aprendizagem, por ser um recurso didático facilitador das práticas educativas pela amplitude de opções que seriam possíveis com a presença da nova tecnologia.

Diante da novidade, diversas escolas começaram a inserir no seu cotidiano este aparato tecnológico com inúmeras funcionalidades, esperando contribuir para o crescimento profissional dos docentes e buscando utilizar a nova tecnologia com criatividade para usufruir das melhores práticas educacionais. A problemática desta questão está associada, no entanto, à forma como se faz uso do recurso tecnológico para melhorar a qualidade de ensino e aprendizagem. Não se pode, nesse processo, esquecer-se do fator humano, que é parte fundamental, pois sem ele a tecnologia não atenderia ao seu objetivo principal, que é a primazia do desempenho do processo de ensino e aprendizagem. A valorização do conhecimento é inerente ao processo de ensino, no qual os professores assumem o papel de mediadores e as ferramentas são auxiliares, cabendo aos professores organizar construtivamente o trabalho pedagógico no cotidiano escolar. Mendes (2016) entende o cotidiano escolar como sendo um lugar particular no qual os acontecimentos históricos podem ser analisados de forma a encontrar indicações de ações que adquirem significado para a compreensão do todo.

Passados 10 anos da instalação desses equipamentos, pergunta-se: em que condições eles estão? Ainda são utilizados e como estão sendo utilizados pelos professores? Há necessidade de mantê-los em sala de aula? Qual a situação atual?

Diagnosticar as condições materiais e históricas da inserção e uso das novas tecnologias educacionais no cotidiano escolar é fundamental para apreender seu significado, sua importância, seus impactos e desdobramentos nos contextos em que se realizam e se situam. Diagnosticar o uso da TV Pendrive como recurso tecnológico auxiliar no processo de ensino e aprendizagem em escolas públicas estaduais no Paraná é basilar. Além disso, é atitude relevante para superar posturas dogmáticas e a-históricas, tão frequentes no senso comum, que atribuem às tecnologias sentidos absolutos de progresso ou desenvolvimento. A aceitação passiva dessas noções valorativas das tecnologias acaba, muitas vezes, por reforçar o apetite pela sua inclusão ingênua, negando sua historicidade e, consequentemente, sua possível incorporação em uma perspectiva crítica.

Os espaços escolares são constantemente ressignificados, ou seja, adquirem novas qualidades, novos sentidos, impactados pelas novas tecnologias no seu cotidiano. E ainda é preciso considerar que os seus sujeitos são capazes de modificar e adequar os ambientes e paisagens com as quais estão habituados a conviver.

Outro fator importante a considerar é que os recursos tecnológicos passaram por uma evolução impactante no decorrer dos últimos anos, possibilitando mudanças técnicas, fazendo com que as pessoas se tornem cada vez menos resistentes e mais confiantes em sua utilização e incorporação no cotidiano escolar. A inserção de novas tecnologias digitais, 
A TV Multimídia nas Práticas Pedagógicas dos Professores nas Escolas Públicas do Estado do Paraná...

como os dispositivos móveis e o uso de aplicativos, proporciona metodologias ativas, colocando o aluno como provedor do conhecimento, pois os aparatos tecnológicos fazem parte do seu cotidiano e são utilizados de forma tranquila e satisfatória.

Especificamente, os objetivos desta investigação são: a) identificar, por meio de questionário de pesquisa quantiqualitativa, se os professores usam o equipamento e se é necessário mantê-lo no ambiente escolar; b) investigar como os professores usam a TV Pendrive, depois de aproximadamente 10 anos de sua inserção nas salas de aula; c) diagnosticar a viabilidade do uso desta ferramenta no processo de ensino e aprendizagem de forma a integrar os conhecimentos técnicos e pedagógicos dos professores.

Por meio da Teoria da Atividade, de Alexei Leontiev, colaborador e discípulo de Vygotsky, buscou-se compreender os diversos elementos teóricos e basilares que constituem a estrutura da ação no uso da TV Multimídia pelos professores da rede pública de ensino do estado do Paraná, a saber: necessidade, intencionalidade, finalidade e condições relacionadas à ação dos sujeitos no cotidiano escolar.

Destaca-se a importância deste estudo sob três aspectos principais: a) analisar o processo de tomadas de decisões pelo docente no contexto escolar, em especial nos processos de uso das novas tecnologias em sala de aula, compreendendo como o uso adequado dos instrumentos tecnológicos lhe permite mediar a aprendizagem nas práticas educativas. Destaca-se, especialmente, que quando as escolhas são intencionais e conscientes, o processo de construção do conhecimento entre o professor e o estudante torna-se dialógico e mediado pelos recursos tecnológicos inseridos no contexto escolar, independentemente do seu porte e da sua localização; b) no caso da inserção da TV Pendrive na sala de aula, não foi uma escolha intencional dos sujeitos envolvidos no processo. A ação governamental objetivava modificar a relação pedagógica entre professor e estudante, esperando que evoluísse para um estágio interativo, mediada pela ferramenta tecnológica. Daí a importância de analisar a correspondência entre as ações governamentais para a inserção de recursos tecnológicos no cotidiano escolar e as intencionalidades dos sujeitos, professores e estudantes que os usam, adequando tais recursos às suas metodologias de ensino e aprendizagem; c) o desenvolvimento das tecnologias de informação e comunicação ocorre de forma muito acelerada e em curto espaço de tempo os artefatos tecnológicos inseridos no ambiente escolar tornam-se obsoletos. No caso da TV Pendrive, inserida há mais de 10 anos, certamente não é diferente. Um investimento altíssimo que rapidamente tende a tornar-se lixo eletrônico. Diagnosticar as condições atuais desses equipamentos, sua manutenção, uso e adequações que podem ser realizadas para prolongar sua vida útil é a destacada importância da contribuição desta pesquisa. 
O artigo está organizado na seguinte ordem: o processo de inclusão deste aparato tecnológico nos meandros escolares; sequencialmente, uma análise da Teoria da Atividade, de Leontiev, fundamentando o processo da mediação tecnológica junto aos sujeitos envolvidos no processo; e, finalizando, o diagnóstico através da coleta e análise dos dados da pesquisa.

\section{MEDIAÇÃO TECNOLÓGICA: UMA ANÁLISE PELA TEORIA DA ATIVIDADE}

A inserção das novas tecnologias no cotidiano escolar permite dar suporte para professores e alunos ao estabelecer estratégias democráticas no processo de ensino e aprendizagem, tornando-se um diferencial para as escolas. Estamos na denominada Revolução tecno-científica-informacional com o advento da internet que promove a democratização da informação de forma atacadista, o que não significa, necessariamente, assimilar mais sabedoria ou conhecimento e, consequentemente, estar destituído do estágio de alienação ou ignorância, pois informação não significa conhecimento. Importante propiciar aos sujeitos envolvidos o discernimento neste oceano da internet e a possibilidade de construir o próprio conhecimento, estimulando o pensamento crítico na constante busca dos conteúdos imprescindíveis para o seu despertar. Ter acesso às novas tecnologias não é suficiente, pois é preciso saber utilizá-las de forma democraticamente coordenada, já que são muitos atores envolvidos no processo de ensino e aprendizagem.

Para que ocorra a relação entre o sujeito e o ambiente em que ele se insere, é preciso uma mediação que permita estímulos e manifestação de respostas para alcançar seu objetivo. Esta conexão é representada pelos diversos artefatos que criam um vínculo deste sujeito com o ambiente em que está inserido.

O sujeito é o agente cujo comportamento será analisado. Os artefatos mediadores são as ferramentas ou ideias empregadas pelo sujeito para o alcance de seu objetivo. $O$ objeto se refere ao material ou situação sobre o qual o sujeito vai agir em interações contínuas com outros sujeitos (MENDES, 2016, p. 36).

Ainda conforme Mendes (2016), a relação destes sujeitos envolvidos na construção do conhecimento é representada na estrutura do gráfico a seguir (Figura 1), em que se compreende que a relação dos sujeitos (professores e alunos) envolvidos com o ambiente (espaço escolar) ocorre pela mediação dos artefatos disponíveis (TV Pendrive). A mediação destes artefatos destaca que não é possível ocorrer uma relação direta dos sujeitos com o espaço escolar, pois requer a presença de elementos mediadores para que possa ser manifestada. 
A TV Multimídia nas Práticas Pedagógicas dos Professores nas Escolas Públicas do Estado do Paraná...

Figura 1 - Conexão mediadora entre sujeito e ambiente

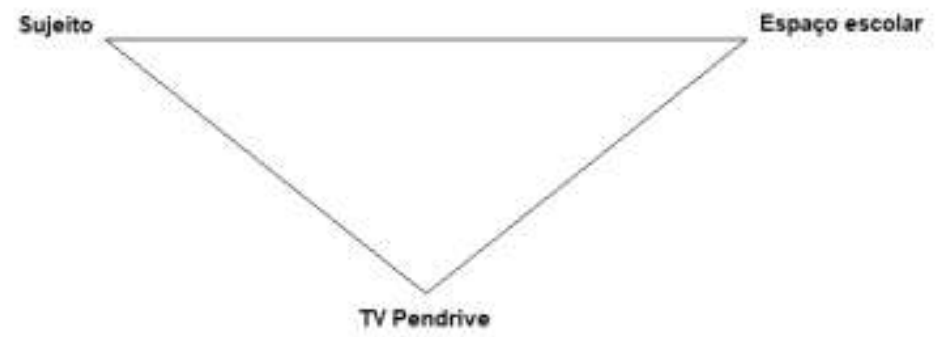

Fonte: Adaptado de Mendes (2016).

Nessa perspectiva, entende-se que na sociedade capitalista as tecnologias da informação e comunicação representam artefatos mediadores concebidos como forma de obter vantagem competitiva num mundo cada vez mais globalizado. $O$ acelerado crescimento das redes de comunicação com tecnologias que modificam radicalmente 0 espaço escolar, em pleno século XXI, faz parte do cotidiano das escolas de maneira desafiadora, impactando o trabalho e a vida dos professores na mediação da aprendizagem dos estudantes, exigindo busca constante pela formação continuada e pela qualificação da atividade laboral, cada vez mais profissionalizada.

De acordo com Leontiev (2014, p. 187), a "[...] característica básica constituinte da atividade é que ela tem um objeto. Na verdade, o próprio conceito de atividade (fazer, Tätigkeit) implica o conceito de objeto da atividade". A condição para a atividade é a presença de um objeto para que ela seja realizada a contento. É presença do objeto que torna possível a atividade. Não é possível imaginar o exercício de uma atividade sem a presença de algum objeto e, conforme esta atividade vai se encontrando com sua determinação no objeto, este vai estimular e orientar a ação, tornando-se o motivo da atividade. Assim, é possível perceber que o reconhecimento da atividade implica na análise de suas intencionalidades, objetivada pelo movimento, e das necessidades, para o desenvolvimento de conteúdos concretos da atividade do sujeito.

Atribuem-se à atividade determinados processos que são fenômenos da consciência humana, destacados pelo fato de tender ao objeto, coincidente sempre com o elemento objetivo que estimula o sujeito e determina atividade motivada. Desta forma, as atividades podem ser provenientes de diversos fatores como: características de espaço e temporalidade, estratégia de execução, aspectos de origem emocional, inclusive com as múltiplas funções mecânicas, físicas e bioquímicas dos sujeitos de forma circular.

Mas a coisa principal não é a estrutura circular enquanto tal, mas o fato de que a reflexão mental do mundo objetivo não é gerada diretamente pelas próprias influências externas, mas pelos processos através dos quais o sujeito chega ao contato prático com o mundo objetivo, e que, por conseguinte, necessariamente obedece suas propriedades, conexões e relações independentes (LEONTIEV, 2014, p. 187). 
Oferecer consentimento à distinção entre as inúmeras atividades é o seu intento, a sua motivação ou finalidade, tornando-se o principal objeto que aponta, evoca e direciona a atividade a um determinado destino, satisfazendo sua necessidade. Conforme contribui valorosamente Leontiev (2014, p. 187), "Isso significa que o agente aferente, que controla o processo da atividade, é primariamente o próprio objeto e, somente secundariamente, sua imagem como o produto subjetivo da atividade, que registra, estabiliza e carrega em si o conteúdo objetivo da atividade".

Da mesma forma que a concepção de atividade está relacionada aos seus diversos motivos, a concepção de ação está vinculada ao seu objetivo ou objeto. Os elementos essenciais que constituem a atividade dos sujeitos são as atitudes que permitem alcançar seus resultados desempenhados pelos seus processos, resultando o atingimento do objetivo final da atividade.

O homem, para satisfazer suas necessidades vitais, constrói por meio da atividade, auxiliado pelos instrumentos que o orientam, o mundo dos objetos. O resultado desejado pode ser atingido com a efetiva participação dos sujeitos na atividade, permitindo mudanças nas suas operações, nas suas atitudes, bem como nas ferramentas para mediar o alcance deste resultado.

A atividade precisa ser estudada juntamente com as operações e ações, pois apesar de exercerem funções diferentes contribuem com o processo de transformação da humanidade e da natureza. Também é possível observar que a atividade contempla um local para que possa ser desenvolvida com regras e divisão de trabalho em classes.

É em atividade que a transição ou tradução do objeto refletido em imagem subjetiva, em ideal, ocorre; ao mesmo tempo, é também em atividade que a transição é alcançada do ideal em resultados objetivos da atividade, seus produtos, em material. Considerada deste ângulo, atividade é um processo de inter-tráfico entre polos opostos, sujeito e objeto (LEONTIEV, 2014, p. 186).

Para esclarecer esta situação entre a atividade/ações/operações, cita-se a cotidianidade docente, que exerce uma atividade de forma composta por inúmeras ações simultâneas ou dispersas no intento de planejar e ministrar suas aulas, engendrar e empregar as avaliações e adequar-se às oportunidades permitidas pelas novas tecnologias, entre outras atividades. Estas ações respeitam de forma indireta as razões da atividade laboral do docente, que é primordialmente a de ensinar. As operações refletem as metodologias operacionais, às quais, por sua vez, são subordinadas às condições objetivas acessíveis, necessárias para realizar as ações. A "[...] escola, os professores, as salas de aula são uma realidade. [...] resta, portanto, voltar a atenção para ela e, com todo o 
A TV Multimídia nas Práticas Pedagógicas dos Professores nas Escolas Públicas do Estado do Paraná...

conhecimento e saber acumulados, ajudá-la a se tornar mais viva, mais dinâmica, mais interessante, mais competente e mais digna" (SILVA, 2016, p. 41).

Diante disso, compreende-se que para Leontiev (2014) a atividade do sujeito ocorre devido às ações, de modo que, se elas fossem eliminadas mentalmente da atividade, não existiria mais atividade. Da mesma forma, a consciência do sujeito, assim como a atividade, não é somatória e sugere que os elementos formativos são determinados pelo movimento da atividade que afeta a vida real do sujeito no seu cotidiano escolar.

A peculiaridade fundamental da atividade é possuir um objeto evidente através da sua existência, independentemente da realização dessa atividade pelo sujeito ou da reflexão mental do mundo objetivo proveniente dos processos pelos quais o sujeito entra em contato com a praticidade do mundo objetivo através da sua atividade. Diante disso, quem controla o processo da atividade é o próprio objeto. O que diferencia as inúmeras atividades são seus objetos. "É o objeto da atividade que a dota de certa orientação. Na terminologia que tenho usado o objeto da atividade é seu motivo. Naturalmente, ele pode ser tanto material quanto ideal; pode ser dado na percepção ou pode existir somente na imaginação, na mente" (LEONTIEV, 2014, p. 189).

Assevera Leontiev (1983) que, para que o sujeito da atividade consiga exercer sua ação, é necessário que o objeto (o seu fim) se relacione de forma consciente com o gerador da atividade (o seu motivo), condicionando a disposição dela, supondo que o sujeito tenha a capacidade de refletir a relação entre o objeto de uma ação e o motivo da atividade da qual essa ação é parte integrante.

Para resumir, a consciência do homem, como sua atividade, não é aditiva. Não é uma superfície plana, nem mesmo uma capacidade que pode ser preenchida com imagens e processos. Também não são as conexões de seus elementos separados. É o movimento interno de seus "elementos formativos" orientados a um movimento geral da atividade que afeta a vida real do indivíduo na sociedade. A atividade do homem é a substância de sua consciência (LEONTIEV, 2014, p. 209).

Para que a manifestação da atividade docente ocorra se faz necessário primeiramente identificar quais são as suas ações separadas, de acordo com os critérios das diferenças diante das suas intencionalidades. Engeström (1987) propôs em gráfico uma estratégia para compreender as atividades dos sujeitos mediadas pelos instrumentos, regras, comunidade e divisão do trabalho tendo em vista os resultados que se pretende atingir (Figura 2).

$\mathrm{Na}$ sequência, é importante identificar os processos das ações que obedecem aos objetivos conscientes e, finalmente, identificar as operações que são dependentes das condições para a realização de um objetivo específico.

O cotidiano dos sujeitos, impactados por estes artefatos tecnológicos, apresenta alterações comportamentais de valores e objetivos motivacionais definindo muitas vezes, 
inclusive, suas opiniões e as peculiaridades das decisões tomadas. Estas tecnologias que dominam o espaço destes indivíduos, seja no ambiente escolar ou fora dele, contribuem para interferir na concepção e valoração do espaço que eles frequentam constantemente, inclusive tornando padronizados seus comportamentos e afetando diretamente também a cotidianidade dos sujeitos envolvidos.

Figura 2 - Estrutura da atividade do aluno Instrumentos ferramentas e signos

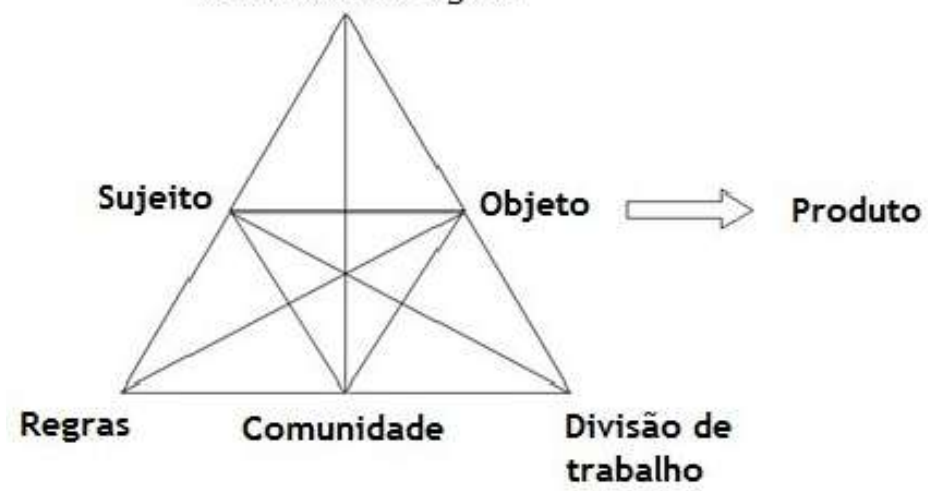

Fonte: Adaptado de Engeström (1987).

Destaca-se que no exercício do papel de aluno escolar, este sujeito precisa ser compreendido numa perspectiva que o considere protagonista do processo educativo, deixando de ser mero coadjuvante, passando a ter suas funções valorizadas pela comunidade escolar em prol de um ambiente de aprendizagem colaborativo, interativo e autônomo, onde todos os integrantes da escola protagonizem o processo educativo. Essa interação é mediada pelas ideias que os discentes têm sobre o espaço escolar em que ela ocorre, através dos conceitos pelos quais vão se apropriando de saberes e à medida que interagem com o professor e com os demais alunos. A estrutura da atividade do aluno pode ser representada na Figura 3 abaixo:

Figura 3 - Estrutura da atividade do aluno

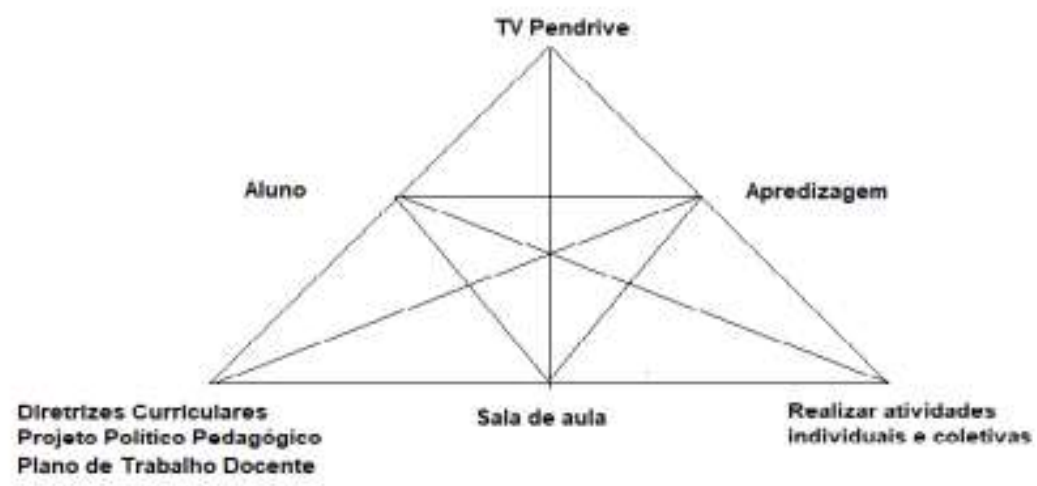

Fonte: Adaptado de Engeström (1987). 
A TV Multimídia nas Práticas Pedagógicas dos Professores nas Escolas Públicas do Estado do Paraná...

$\mathrm{Na}$ estrutura apresentada, o aluno tem o propósito de, pela atividade, relacionar-se com o ambiente ao apropriar-se de saberes através dos artefatos e materiais didáticos, ao desenvolver atitudes e reflexões sobre o espaço escolar e principalmente sobre o meio no qual está inserido. Sua atividade consiste em interagir e refletir sobre ações que possibilitam melhorar a qualidade do seu espaço ao desenvolver ações de responsabilidade que podem ser mediadas pelos conhecimentos adquiridos no processo de interação com a comunidade e por materiais didáticos.

A educação sistematizada apresenta-se impactada por novas tecnologias, que estão evidentemente presentes na sociedade em geral, passando a constituir parte do seu processo ao receber influências destes artefatos que outrora eram apresentadas apenas pelos livros didáticos. Exemplifica-se com a utilização da TV Pendrive como meio para propiciar que a informação seja pública e democrática, tornando-se para o professor uma grande oportunidade de agregar valor ao ensino sistematizado sem, obviamente, substituir o desempenho e a atuação fundamental do docente.

$\mathrm{Na}$ atuação docente, auxiliado pela tecnologia na sala de aula, o professor precisa manter uma postura responsável na condução do processo associativo entre tecnologia e conhecimento, pois estas tecnologias contemporâneas no contexto do ambiente escolar necessitam de um mediador com sapiência para discernir que elas são apenas instrumentos auxiliares na atuação do professor.

Os desafios encontrados pelo docente no século XXI para direcionar os alunos aos caminhos adequados na construção do conhecimento podem ser manifestados nas ferramentas de materiais disponíveis na constituição da estrutura da atividade de professor. Destaca-se a importância de o professor compartilhar os objetivos das suas atividades com outros sujeitos do processo (direção, coordenação pedagógica, alunos, funcionários e comunidade), pois sua responsabilidade nesta divisão de tarefas do trabalho é proporcionar reflexões aos alunos quanto à responsabilidade na construção do conhecimento elaborado. A estrutura da atividade do professor está representada na figura 4 a seguir.

A mediação do professor nas diversas atribuições das atividades educativas pode ser respaldada pelas Diretrizes e Parâmetros Curriculares da respectiva área e pelo Projeto Político Pedagógico. O desígnio da atividade do professor é criar condições para a conscientização dos alunos quanto à necessidade do desenvolvimento da consciência e de atitudes relacionadas às tecnologias, que podem ser manifestadas na mediação dos materiais didáticos de ensino, ou mesmo pelas ferramentas tecnológicas disponíveis.

Diante do exposto, e mediante abordagem viabilizada pela Teoria da Atividade, percebe-se que a conscientização dos alunos é possibilitada pela constante busca de caminhos alternativos e de novas estratégias desenvolvidas pelas suas atividades no 
contexto escolar. As novas tecnologias, enquanto aparatos que propiciam 0 desenvolvimento de atividades no âmbito escolar têm influenciado constantemente os sujeitos partícipes do processo de ensino e aprendizagem. Este pode ser conduzido de diversas maneiras, desde a sua concepção, sua comunicação aos sujeitos envolvidos, bem como pode permitir nova interferência do mundo em que está inserido.

Figura 4 - Estrutura da atividade do professor

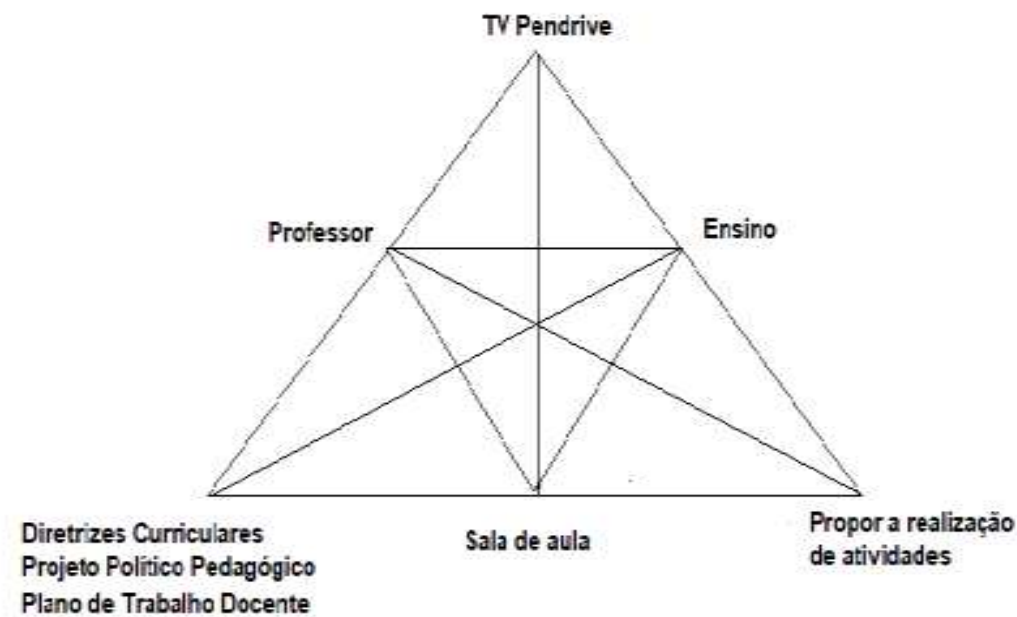

Fonte: Adaptado de Engeström (1987).

Desta forma, promover mudanças significativas no desenvolvimento das atividades pedagógicas, bem como redefinir a relação aluno-professor para que aconteça o incremento das ferramentas e materiais didáticos e tecnológicos - neste caso, a TV Pendrive -, permite gerar mudanças na atuação pedagógica. O papel de intermediação exercido por este artefato evidencia que a relação entre o indivíduo e o meio em que está inserido não acontece de maneira direta, mas é sempre culturalmente mediada; o uso de elementos mediadores caracteriza a relação entre o ser humano e o mundo.

\section{CENÁRIO DA TV MULTIMÍDIA NA ESCOLA PÚBLICA DO PARANÁ}

Esta pesquisa foi realizada com docentes de diversas disciplinas do Ensino Fundamental e Médio da rede pública do estado do Paraná - viabilizada pelas redes sociais nos grupos de Facebook, rede de e-mails e grupos de WhatsApp - que receberam algumas indagações, pois a TV Pendrive está presente no seu cotidiano escolar. Objetivou-se diagnosticar as concepções frequentes no processo de ensino e aprendizagem nas diversas disciplinas que compõem a base curricular no Paraná. A metodologia utilizada foi o levantamento de dados, através de 10 perguntas objetivas, com o intuito de diagnosticar a inserção e a utilização da TV Pendrive nas salas de aulas de diversos colégios da rede 
A TV Multimídia nas Práticas Pedagógicas dos Professores nas Escolas Públicas do Estado do Paraná...

estadual de ensino no Paraná. As questões foram disponibilizadas pelo Google Formulários, um dos aplicativos que faz parte do Google Drive.

Julgou-se premente indagar sobre a importância de modificar as práticas educacionais no ambiente escolar dos sujeitos envolvidos para que se favoreçam destes novos aparatos tecnológicos que chegam às escolas públicas paranaenses. Com esta intencionalidade, apresentaram-se questões aos docentes objetivando diagnosticar a compreensão deles sobre o uso da TV Pendrive na prática pedagógica, bem como investigar as possibilidades da integração deste artefato tecnológico como instrumento de ensino que aprimore o processo e os resultados da aprendizagem.

Destaca-se que o emprego do equipamento TV Pendrive foi copiado da experiência cubana e acreditava-se ser de fácil utilização, pois o professor já manuseava o televisor na sua residência. Porém, as características técnicas são perceptíveis de forma bastante diferenciada entre o aparelho doméstico e aquele disponibilizado no ambiente escolar. Conforme Silva (2016, p. 38), "[...] no Brasil, um projeto inspirado nas realizações de Cuba pretendeu, igualmente, assegurar a possibilidade de se trazer às salas de aula conteúdos disponíveis na rede de computadores, em um ambiente desprovido de conectividade".

Com aspectos inovadores no ambiente da sala de aula e sendo impactados repentinamente pela "imposição" desta tecnologia, os professores se mostraram reticentes e apresentaram resistência ao utilizar o novo dispositivo. Dessa forma, iniciou-se um trabalho de sensibilização desses professores em relação ao uso das tecnologias, buscando o apoio das direções e equipes pedagógicas. Outra dificuldade encontrada foi conseguir realizar um trabalho efetivo e contínuo com os professores, pois o método de trabalho da Coordenação Regional de Tecnologia Educacional parte do princípio de prestar-se assessoria in loco (no local de trabalho do professor, ou seja, na escola onde leciona). Conforme ressalta Basniak (2014), a disponibilização de grande quantidade de material no Portal Dia a Dia Educação (disponível em: <http://www.diaadia.pr.gov.br/>), muitos dos quais dinâmicos, como vídeos e sons, gerou a necessidade de que esse material dinâmico chegasse aos alunos. Sendo assim, foi desenvolvida e implantada a TV Multimídia em vinte e duas mil salas de aula do estado do Paraná.

Entretanto, percebe-se que alguns docentes ainda relutam na utilização da tecnologia da TV Pendrive quando disponível, por considerarem-na arcaica ou já sendo substituída paulatinamente por outras tecnologias. Nos diversos aspectos que constituem estes novos processos das práticas pedagógicas, a instalação da TV Pendrive no ambiente da sala de aula foi feita com o intuito de contribuir, com aspecto diferenciado, no repertório de ferramentas didático-pedagógicas, que auxiliam o professor e proporcionam mais dinamicidade no processo de ensino e aprendizagem. 
Pretendendo encontrar maior número possível de respostas para a incômoda condição da TV Pendrive, foram feitas algumas indagações aos docentes sobre a utilização e permanência dela no espaço escolar. O objetivo era diagnosticar se ainda faz sentido que esta tecnologia permaneça no ambiente escolar, pois se observa que está em ritmo de desuso, dispensável na sala de aula, tornando-se até mesmo um entulho ou algo desconfortável visualmente.

Como resultado quantitativo, obteve-se a participação de 309 professores respondentes, dispersos em toda rede pública de ensino do estado do Paraná. Os participantes informaram que lecionavam as seguintes disciplinas (na sequência do percentual estão informados os números absolutos entre parênteses): Língua Portuguesa 12,6\% (39); Biologia 8,4\% (26), Educação Física 6,5\% (20); Filosofia 6,8\% (21); História 12,3\% (39); Física 1,9\% (6); Artes 7,1\% (22); Sociologia 4,9\% (16); Geografia 11\% (35); Química 1,9\% (6); Inglês 5,5\% (18); Matemática 7,1\% (23); Atividades extracurriculares 1.2\% (4); Pedagoga 1,9\% (6); Ciências 6\% (12); Contabilidade 0,6\% (2); Administração 0,6\% (2); Educação especial 0,3\% (1); Informática 1,9\% (6); Espanhol 1,2\% (4); Psicologia da Educação 0,3\% (1).

Em consonância com os dados apresentados acima, a pesquisa mostrou que há disparidade significativa quanto à distribuição dos vínculos empregatícios dos respondentes, pois $77,7 \%$ pertencem ao Quadro Próprio do Magistério e os demais pertencem ao quadro regido por contrato específico do Processo Seletivo Simplificado (22,3\%). Quanto ao tempo que lecionam no estado do Paraná, os entrevistados responderam: mais de 20 anos (26,9\%); entre 12 e 20 anos (22,7\%); entre oito anos e 12 anos (17,2\%); entre um e cinco anos (15,9\%); entre cinco e oito anos (14,2\%); e até um ano $(3,2 \%)$.

Estes dados revelam que a maioria dos professores pesquisados possui estabilidade de emprego, adquirida por concurso público realizado há mais de 20 anos, quando o cenário no ambiente escolar era bastante diverso do contemporâneo, em que estão presentes as tecnologias em questão. Na compreensão de Mendes (2016, p. 140) "[...] assim, com o tempo se desenvolve uma familiaridade com o lugar, o que possibilita que cada vez mais passe a ser conhecido pelas pessoas que the 'dão vida'”. Praticava-se uma educação tradicional diferente da compreensão atual, eram utilizadas ferramentas como quadro, giz e livro didático, que atualmente tornam-se insuficientes no processo de ensino e aprendizagem diante das diversas opções das novas tecnologias.

O perfil deste profissional apresenta uma passividade maior diante dos desafios proporcionados pelas novas tecnologias e diante da nova geração caracterizada pela dinamicidade e pelo acesso facilitado às informações. Apresenta ainda algum resquício de resistência e falta de atitude pessoal, limitando sua atividade laboral utilizando apenas recursos não digitais. Nessa perspectiva, o espaço escolar torna-se o lugar onde é possível 
A TV Multimídia nas Práticas Pedagógicas dos Professores nas Escolas Públicas do Estado do Paraná...

criar diversos significados quando começa a fazer sentido para os sujeitos capazes de produzir identidade com o lugar.

Em maioria (68\%), os professores responderam que utilizam a TV Pendrive; não a utilizam 32\% dos respondentes. A maior parte dos que a utiliza apresenta característica autodidata na aprendizagem do manuseio, pois $68,6 \%$ não receberam qualquer treinamento; apenas 31,4\% receberam treinamento. Para Leontiev (1992), o exercício da atividade ocorre em um sistema estruturado e com desenvolvimento próprio na orientação do sujeito no mundo dos objetos. Compreende-se, portanto, a necessidade de buscar a informação técnica de forma autônoma e independente do empregador.

Dos docentes que responderam quais recursos utilizam na TV Pendrive (questão de múltipla escolha), 210 respostas correspondem a vídeo/imagem, 114 responderam a apresentação de conteúdo, 106 responderam que utilizam música e 94 informaram não utilizar. No entender de Mendes (2016, p. 38), "[...] a atividade é decorrente de um motivo que é o objeto em transformação. O motivo é o que a consciência desenvolve tendo em vista suprir uma necessidade". Mesmo com a facilidade de acesso ao conteúdo de vídeos no popular site Youtube relacionados aos temas estudados em sala de aula, verificou-se grande quantidade de respondentes que não utilizam o equipamento.

Salienta-se, ainda, que 143 respondentes compreendem que a TV Pendrive é um facilitador nas aulas, 115 responderam que ela contribui significativamente para a qualidade das aulas, 30 responderam que é uma etapa do processo e 92 responderam que não utilizam. Destaca Mendes (2016, p. 38) que "[...] o ser humano tem consciência das suas necessidades e estabelece motivos para atendê-las", confirmando os números da resposta anterior, em que muitos docentes desconsideram o uso de tecnologia no ambiente escolar.

Na pesquisa realizada preocupou-se em investigar o motivo por que muitos docentes não estão utilizando a tecnologia e 36,6\% indicaram que a TV Pendrive apresenta problemas técnicos, o que justifica a grande quantidade de televisores sendo retirados das salas de aula e descartados para locais inacessíveis, sem reposição. A utilização de outros recursos tecnológicos foi apontada por $15,5 \%$ dos respondentes; $6,5 \%$ responderam que, na TV Pendrive, os discentes não conseguem visualizar as imagens ou o equipamento possui som inadequado. Nesta perspectiva, a ação torna-se um componente destacado da atividade humana, pois o sujeito se torna consciente de acordo com a ação que origina. Leontiev (2006, p. 69), quando faz referência ao estímulo de uma ação, afirma que "[...] por si mesmo, não estimula o agir. Para que a ação surja e seja executada é necessário que seu objetivo apareça para o sujeito, em sua relação com o motivo da atividade da qual ele faz parte".

Muitos apontaram que demanda muito tempo para preparar as aulas $(5,2 \%)$, o que consolida a reclamação dos professores diante da redução de duas horas atividades no seu 
cronograma de trabalho. Esta decisão governamental restringe o tempo dos docentes para se aperfeiçoar e preparar melhores aulas. Apontaram que não sabem utilizar o equipamento $2,9 \%$ e não Ihes é ofertada alternativa tecnológica para utilizar em sala de aula. Muitos profissionais (175 deles) apontaram como desafio a formatação adequada de arquivos para que sejam compatíveis com a TV Pendrive; a instalação inadequada foi apontada por 84 respondentes; e novamente destaca-se o tempo para preparar as aulas, apontado por 73 respondentes. O domínio de questões técnicas foi apontado por 30 deles. No entendimento de Leontiev (1992), a atividade humana é compreendida por ações e operações, e a participação do indivíduo na atividade torna-se fundamental, com atitudes para alcançar objetivos previamente definidos em sua consciência. Os professores compreendem que o sucesso da sua execução é resultado do seu planejamento. Verifica-se neste cenário a falta de orientação e treinamento adequado aos professores para que façam uso eficiente desta tecnologia.

Encerrando o questionário, indagou-se sobre a necessidade da permanência da TV Pendrive no ambiente escolar. A maioria dos respondentes $(71,5 \%)$ considera importante a permanência; os demais $(28,5 \%)$ consideram-na desnecessária. Nesta perspectiva, baseando-se em Leontiev (1983), compreende-se que a atividade do professor se configura na forma de ações, confirmando o conceito de atividade: somente pode ser definida se tiver como referência a sua motivação (material ou ideal), aquilo que faz sentido. Devido à falta de opção dos professores, eles se motivam a utilizar esta ferramenta auxiliar no processo de ensino e aprendizagem.

Observa-se na atuação profissional um desdém, até mesmo pelo sucateamento deste instrumento diante de novas e constantes opções tecnológicas. Muitos dos profissionais, que no primeiro momento de impacto ficaram impressionados com a inclusão da TV Pendrive, atualmente não a utilizam devido às más condições técnicas, pela falta de substituição ou de conserto do aparelho.

Fato confirmado pelo desuso e pelo desinteresse dos docentes pela TV Pendrive foi o recente evento realizado pela Secretaria de Estado da Educação do Paraná intitulado $2^{\circ}$ Encontro Estadual de Tecnologias Educacionais: Inovação e Criatividade na Educação Paranaense, ocorrido de 7 a 9 de novembro de 2017, em Curitiba - PR, nas dependências da Diretoria de Políticas e Tecnologias Educacionais (DITEC), órgão da referida Secretaria, responsável pelo planejamento, desenvolvimento e avaliação dos processos de tecnologias de informação e comunicação na Educação Básica. O evento proporcionou a realização de oficinas, palestras, mesas-redondas, relatos de experiências, Hackathon de Tecnologias Assistivas e um Festival de Invenção e Criatividade (FIC), com grande celebração do espírito inventivo, colaborativo e "mão na massa" da educação brasileira. Foram apresentados 296 trabalhos desenvolvidos pelos professores, em cinco eixos temáticos: 
A TV Multimídia nas Práticas Pedagógicas dos Professores nas Escolas Públicas do Estado do Paraná...

mídia e educação; educação inclusiva e tecnologia; empoderamento e tecnologia; ressignificação dos espaços escolares; e inovação e tecnologia na educação.

As oficinas, relatos de experiência, mesas-redondas e palestras foram desenvolvidos e apresentados nas diversas salas de aula em ótimo estado de conservação. Todas as salas tinham à disposição Datashow, computador, som adequado e encontrava-se instalada a TV Pendrive em perfeito estado de uso. Porém, a qualidade física da sala de aula é algo incomum nas escolas do estado do Paraná.

Observou-se pela participação direta no evento que em momento algum se apresentou a TV Pendrive como objeto de estudo ou uso. Na relação dos 296 trabalhos aprovados e apresentados, nenhum deles fez referência ao uso da tecnologia TV Pendrive. Evidentemente, destaca-se a relevância do fato observado como comprovação do desinteresse e do gradativo desuso desta tecnologia, cotidianamente um objeto deslocado nos espaços escolares.

\section{CONSIDERAÇÕES FINAIS}

Diversas inquietações motivaram esta pesquisa sobre o cenário real de utilização e permanência da TV Multimídia no espaço escolar. Dentre elas, a preocupação com a rapidez com que ocorre o desenvolvimento científico e tecnológico e sua aplicabilidade em forma de ferramentas auxiliares nas práticas educativas, e a necessidade de pensar novas formas de interação com estes aparatos no espaço escolar.

A partir dos princípios da Teoria da Atividade torna-se importante analisar as atitudes individuais dos sujeitos no contexto do ambiente escolar, pois é neste espaço que elas ganham significado, interagindo com os materiais didáticos e tecnológicos na apropriação de saberes. Nessa continuidade, as relações entre os papéis dos sujeitos estabelecidos no espaço escolar para alcançar os propósitos estabelecidos, e tendo como base a Teoria da Atividade, dinamizam sistemas de atividade dos sujeitos na busca da compreensão das relações sociais que ali acontecem.

Diante disso, foi possível detectar que a informação é vital para o funcionamento de uma escola, que está inserida neste turbilhão de constantes mudanças. Porém, não basta reter informações. É necessário filtrá-las, organizá-las, analisá-las, processá-las e, principalmente, utilizá-las de maneira estratégica, proporcionando ao discente ampliar o acesso ao conhecimento. Conforme Silva (2016), os recursos tecnológicos não asseguram, por si, a qualidade da educação escolar, pois a escola precisa investir na organização deste patrimônio chamado informação, que é a força motriz que permite que ela se mantenha viva e atuante. Registra-se que no entendimento de Leontiev (1983), o fato gerador de uma atividade ocorre para satisfazer uma necessidade, que só pode ser realizada quando 
encontra esse objeto. Neste aspecto, compreende-se que necessidade, objeto e motivo estruturam uma atividade quando relacionados pelas ações, tornando-se subordinados ao objetivo estabelecido.

Partindo notadamente do objetivo de diagnosticar a utilização da TV Pendrive à luz da Teoria da Atividade, de Leontiev (2014), constatou-se que as novas tecnologias permitem agilidade no acesso às informações nas atividades do cotidiano escolar, como também estreitam o relacionamento entre professores e alunos nesta infindável busca pelo conhecimento. A tecnologia existente entre esses dois elos está cada vez mais avançada, permitindo o acesso às informações relevantes e atualizadas para a tomada de decisões com mais rapidez, serenidade e segurança. É preciso pensar que esse tipo de situação, pelo fato de envolver diversos sujeitos na utilização das ferramentas tecnológicas, precisa ser muito bem planejado entre os envolvidos para que a comunicação entre eles seja eficiente e confiável. A tecnologia da informação está em constante evolução, de modo que os professores e as escolas devem estar atentos para conseguirem aproveitar o que ela oferece de melhor, preparar os recursos internos e adequar o ambiente para a sua utilização.

É necessário reconhecer que as novas tecnologias estão em constantes mudanças no ambiente escolar e acompanhá-las para ter agilidade e qualidade na assimilação do conhecimento. Ao diagnosticar, a partir dos pressupostos da Teoria da Atividade, as relações que se estabelecem na integração entre os sujeitos das escolas diante das possibilidades ofertadas pelos aparatos nelas presentes, é essencial que ocorra a troca de informação, fator de sucesso que possibilita a tomada de decisões rápidas, à frente das adversidades.

Evidencia-se, desta forma, que a investigação contribuiu para esclarecer que a maioria dos docentes pesquisados ainda utiliza a TV Pendrive, pois não Ihes é ofertada alternativa tecnológica para acompanhar as constantes mudanças. Compreende-se que determinadas tecnologias permitem o acesso imediato e facilitado às informações e trazem mudanças comportamentais consideráveis nos discentes, trazidas do ambiente externo. Porém, o grande desafio percebido está no docente que não busca alternativas tecnológicas além daquelas apresentadas no ambiente escolar pelo empregador.

Pelo exposto, compreende-se que a TV Pendrive auxilia sobremaneira nas práticas educacionais de ensino e aprendizagem, pois são inúmeros os dados que devem ser inseridos e processados no sistema de informação. Considerando sua importância para o trabalho pedagógica nas escolas, são essenciais a sua manutenção e conservação.

Nessa perspectiva, entende-se que o diagnóstico aqui apresentado pode expressar um referencial significativo para a reflexão pedagógica estabelecida nas práticas educativas 
A TV Multimídia nas Práticas Pedagógicas dos Professores nas Escolas Públicas do Estado do Paraná...

no processo de ensino e aprendizagem contemporâneo nas escolas públicas do estado do Paraná.

\section{REFERÊNCIAS}

BASNIAK, M. I. Políticas de tecnologias na educação: o programa Paraná Digital. Tese (Doutorado em Educação) - Universidade Federal do Paraná, Curitiba, 2014.

ENGESTRÖM, Y. Learning by expanding: an activity-theoretical approach to development research. Finland: Orienta-konsultit, 1987.

JACKIW, E. A tv multimídia nas escolas estaduais do Paraná: os desafios pedagógicos na prática docente. Dissertação (Mestrado em Educação) - Universidade Federal do Paraná, Curitiba, 2011.

LEONTIEV, A. N. Atividade e consciência. Revista Dialectus, Fortaleza, ano 2, n. 4, p. 184210, jan./ jun. 2014.

Atividade, consciência e personalidade. Havana: Pueblo e Educação, 1983.

Ecce homo. Methodological problems of the activity theoretical approach.

Multidisciplinary Newsletter for Activity Theory, New York, n. 11/12, p. 41- 44, 1992.

. Uma contribuição à teoria do desenvolvimento da psique infantil. In: VIGOTSKI, L. S.; LURIA, A. R.; LEONTIEV, A. N. Linguagem, desenvolvimento e aprendizagem. São Paulo: Ícone, 2006. p. 59-83.

MENDES, J. R. Geografia e educação ambiental: uma abordagem a partir da teoria da atividade. Tese (Doutorado em Geografia) - Universidade Federal do Paraná, Curitiba, 2016.

SILVA, M. R. de M. e. Tecnologias digitais para uso nas escolas públicas de educação básica: TV multimídia. Dissertação (Mestrado em Informática) - Universidade Federal do Paraná, Curitiba, 2016. 